\title{
Association of a hypoxia-inducible factor-3a gene polymorphism with superovulation traits in Changbaishan black cattle
}

\author{
Q. Deng ${ }^{1 *}$, Y. Gao ${ }^{1 *}$, H. Jiang ${ }^{1}$, C.Z. Chen ${ }^{1}$, C.H. Li ${ }^{1}$, W.L. Yu ${ }^{2}$, X. Chen ${ }^{3}$ and \\ J.B. Zhang ${ }^{1,4}$ \\ ${ }^{1}$ Laboratory Animal Center, College of Animal Sciences, Jilin University, \\ Changchun, China \\ ${ }^{2}$ Beijing AnBo Embryo Biotech Center, Beijing, China \\ ${ }^{3}$ Department of pharmacology, College of Basic Medical Sciences, Jilin University, \\ Changchun, China \\ ${ }^{4} \mathrm{Jilin}$ Provincial Key Laboratory of Animal Embryo Engineering, \\ College of Veterinary Medicine, Jilin University, Changchun, China \\ ${ }^{*}$ These authors contributed equally to this study. \\ Corresponding author: J.B. Zhang / X. Chen \\ E-mail: zhangjiabao515@163.com / chenx@jlu.edu.cn
}

Genet. Mol. Res. 14 (4): 14539-14547 (2015)

Received April 25, 2015

Accepted July 6, 2015

Published November 18, 2015

DOI http://dx.doi.org/10.4238/2015.November.18.17

\begin{abstract}
This study was designed to examine a single nucleotide polymorphism (SNP) in the HIF-3 $\alpha$ gene in three hundred Changbaishan black cattle using PCR-restriction fragment length polymorphism to determine whether there is an association between this SNP and superovulation. The cloning and sequencing results indicate that the polymorphism is due to a point mutation at the 278-bp position in the HIF$3 \alpha$ gene, resulting in 3 genotypes (AA, $A B$, and $B B$ ). Association analysis indicated that the polymorphism has a significant effect on the number of unfertilized embryos (NUE) $(P<0.05)$ in the cattle. Cattle with genotype $B B$ had a higher NUE than those with genotype AA, but the difference in NUE between $A B$ and $A A$ or $B B$ was not significant. The polymorphism
\end{abstract}


also has a highly significant effect on the number of degenerative embryos (NDE) and the number of total embryos (NTE) $(P<0.01)$. Genotype BB was associated with a higher NDE than $A A$, but the difference in NDE between $A B$ and $A A$ or $B B$ was not significant. Genotype $B B$ showed a higher NTE than $A A$ or $A B$, but the difference in NTE between $A A$ and $A B$ was not significant. No significant conclusions could be drawn with respect to susceptibility to other traits. HIF-3 $\alpha$ could serve as a useful biomarker for donor selection, superovulation improvement, and assisted fertility.

Key words: HIF-3a; Polymorphism; Superovulation traits; Cattle

\section{INTRODUCTION}

Superovulation is a major component of successful embryo transfer techniques that are used worldwide to produce valuable bovine embryos for breeding (Mapletoft and Hasler, 2005). However, the total number of transferable embryos has not changed markedly in the last 20 years, and the application of multiple ovulation and embryo transfer (MOET) technologies in animal industries is approaching a plateau. The major limitations to the development of MOET are the reliance on follicle stimulating hormone (FSH)-induced superovulation and the large variability in animal response to treatments (Hasler, 2003). Improvements in reproduction by traditional selective breeding methods have proved to be difficult due to low heritability and long reproductive cycles. It has been indicated that single nucleotide polymorphisms (SNPs) may become the preferred predictive marker of ovarian response (Fauser et al., 2008). The candidate gene approach provides an early breeding tool that could accelerate improvements in reproduction.

It is well known that oxygen homeostasis is fundamental for the maintenance of proper cellular functions and deregulation of oxygen dependent cellular processes is associated with developmental disorders. The central regulator of the mammalian oxygen-sensing pathway is a family of transcription factors called hypoxia-inducible factors (HIF), which trans-activate the expression of more than 60 genes in response to compromised oxygen tension (Maynard and Ohh, 2004, 2007).

HIF is a heterodimeric complex composed of an $\alpha$ or $\beta$ subunit (Maynard and Ohh, 2004, 2007). To date, three $\alpha$ subunits ( $H I F-1 \alpha, H I F-2 \alpha$, and $H I F-3 \alpha)$ and one $\beta$ subunit (HIF-1 $\beta$, also called aryl hydrocarbon receptor nuclear translocator) have been identified (Wang et al., 1995; Wenger and Gassmann, 1997).

Hypoxia has been shown to have no effect on mRNA levels of $H I F-1 \alpha, H I F-1 \beta$, and $H I F-2 \alpha$, but HIF-3 $\alpha$ mRNA levels increased in all organs examined after $2 \mathrm{~h}$ of hypoxia (Heidbreder et al., 2003). Induction at the transcriptional level is a unique feature of HIF-3a, which may represent a rapidly reacting component of the HIF system for protection against hypoxic damage (Heidbreder et al., 2003).

Of the three hypoxia-inducible transcription factor family members identified in mammals

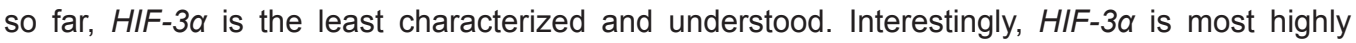
expressed in the human placenta and myocardium (Maynard et al., 2003). Because the amount of oxygen supplied from maternal blood to embryos through the placenta is limited, embryos are continuously exposed to lower oxygen tension (Genbacev et al., 2001). The availability of oxygen is limited in the uterus and embryos are continuously hypoxic (Lee et al., 2001). Under such conditions, it is likely that HIF-a proteins are not degraded but accumulate in the nucleus.

Given that both HIF-1 $\alpha$ and HIF-2 $\alpha$ are required for early embryonic development (lyer et al., 1998; Tian et al., 1998; Peng et al., 2000), HIF activity must be elaborately regulated in embryos. 
The HIF-3 $\alpha$ transcript was expressed in virtually all embryonic and adult tissues examined. Gene expression analysis by RT-PCR revealed that HIF-3a mRNA is broadly expressed in various tissues of the mouse during embryonic and neonatal stages and that HIF-3a expression gradually decreases at 15 days postnatal (Yamashita et al., 2008).

Consequently, HIF-3a was chosen as a candidate gene for association with superovulation traits in the current study. Here, SNPs were examined using PCR-restriction fragment length polymorphism (PCR-RFLP) sequencing and RT-PCR. The aim of this study was to clarify the association between the HIF-3a gene polymorphism and superovulation traits in Changbaishan black cattle and to detect mRNA expression levels of HIF-3 $\alpha$ at different early embryo developmental stages. These results validate the involvement of $\mathrm{HIF-3 \alpha}$ in superovulation responsiveness.

\section{MATERIAL AND METHODS}

\section{Chemicals and reagents}

All chemicals and reagents were purchased from Sigma (Shanghai, China) unless otherwise noted.

\section{Superovulation procedure and embryo collection}

Changbaishan black cattle are beef cattle that originated from an introduced Japanese black cattle line hybridized with local cattle. Our experiments were conducted from June to September in Jilin, China $\left(127.33^{\circ} \mathrm{E}, 43.67^{\circ} \mathrm{N}\right)$. Before the superovulation treatment, Changbaishan black cattle, including nulliparous (ages 11 to 13 months) and multiparous cattle (ages 24 to 48 months), were selected by trans-rectal palpation for the absence of gynecological abnormalities. All the cattle received ad libitum feeding with a special high-protein, high-energy diet.

Superovulation was induced in the selected cattle using a protocol from the Beijing AnBo Embryo Biotech Center, the 16-day FSH - CIDR [EAZI Breed ${ }^{\mathrm{TM}}$ CIDR (progesterone), cattle insert] - prostaglandin (PG)- luteinizing hormone releasing hormone (LHRH) (FSH-CIDR-PG-LHRH) method, which is described in detail in the Supplementary File. Each cattle in estrus received two doses of frozen semen, which was collected by artificial vagina from one fertile Wagyu bull at 12-h intervals.

An experienced technician recovered the embryos and ova using a standard nonsurgical uterine flushing technique 6 days after artificial insemination. The initial search and evaluation of embryos and ova were carried out using a stereomicroscope at magnifications of 10X to 70X. Recovered viable embryos were evaluated at $70 \mathrm{X}$ magnification on the basis of the compactness and homogeneity of the cell mass, and cell assessment was conducted according to the published paper by Lindner and Wright (1983).

Briefly, cells were classified as M1 (morulae, Grade 1: embryos with single or small extruded blastomeres comprising less than $15 \%$ of the total cellular material), M2 (morulae, Grade 2: large cells or individual blastomeres extruded from the embryonic mass that make up more than $15 \%$ but less than $50 \%$ of the total cellular material), or blastocoel. Embryos with blastomeres that contained nuclei but were too underdeveloped to be considered viable were classified as degenerate. An unfertilized ovum was designated when there was no indication of cleavage or when all cytoplasmic fragments lacked nuclei.

Experiments were performed in accordance with the 'Guiding principles in the use of 
animals', adopted by the Chinese Association for Laboratory Animal Sciences. The study plan was approved by the Ethics Committee on the Use and Care of Animals, Jilin University.

\section{Genomic DNA extraction}

Approximately $2 \mathrm{~mL}$ blood per cattle was aseptically collected from the jugular vein immediately after recovery of the embryos, maintained in a tube containing ethylene diamine tetraacetic acid, and held on ice until delivery to the laboratory where it was stored at $-20^{\circ} \mathrm{C}$.

Genomic DNA was extracted using the Blood Genomic DNA Miniprep kit (Axygen, Hangzhou, China) and detected using $0.8 \%$ agarose gel electrophoresis. The DNA samples were dissolved in TE buffer and stored at $-80^{\circ} \mathrm{C}$ for future use.

\section{Primer synthesis and PCR amplification}

Primers were designed based on the Bos taurus breed Hereford chromosome 18 sequence using the Oligo 6.0 software (http://www.oligo.net/). The upstream primer was 5'-CTGGGCAGTTG CTACTGTTCCTAT-3' and the downstream primer was 5'-AGTCCCGTCCAGGATTGGT-3'. The primers were synthesized by Shanghai Sangon Biological Engineering Technology \& Services Co., Ltd., Shanghai, China.

The PCR mixture contained $50 \mathrm{ng}$ DNA template, $10 \mathrm{pM}$ upstream and downstream primer, $2.5 \mathrm{mM}$ dNTP mixture, $1.5 \mathrm{mM} \mathrm{MgCl}_{2}$, and $1 \mathrm{U}$ Taq DNA polymerase in a $20-\mu \mathrm{L}$ reaction volume. Amplification conditions consisted of $95^{\circ} \mathrm{C}$ for $5 \mathrm{~min}$, followed by 35 cycles of $94^{\circ} \mathrm{C}$ for 30 $\mathrm{s}, 60^{\circ} \mathrm{C}$ for $30 \mathrm{~s}$, and $72^{\circ} \mathrm{C}$ for $30 \mathrm{~s}$, and a final step at $72^{\circ} \mathrm{C}$ for $10 \mathrm{~min}$. The amplification products were run on a $1 \%$ agarose gel and visualized using a UV transilluminator.

\section{Genetic variation identification and sequencing}

To detect the HIF-3a SNP, PCR products were digested with the restriction endonuclease Alw44 I (MBI Fermentas Life Science, Ontario, Canada) according to the manufacturer protocol. The mixture contained $5 \mu \mathrm{L} \mathrm{PCR}$ product, 10X digestion buffer, and $10 \mathrm{U}$ enzyme, and was digested at $37^{\circ} \mathrm{C}$ for $8 \mathrm{~h}$. Fragments were run on a $2 \%$ agarose gel and stained with ethidium bromide. Three genotypes were classified based on the band patterns. PCR products showing homozygous genotypes were cloned and sequenced by Shanghai Sangon Biological Engineering Technology \& Services Co. Ltd.

\section{Statistical analysis}

Associations between HIF-3a genotypes and superovulation traits were analyzed using the general linear model (GLM) procedure of SPSS version 13.0. The linear model is:

$$
\mathrm{Y}_{\mathrm{ijk}}=\mu+\mathrm{P}_{\mathrm{i}}+\mathrm{M}_{\mathrm{j}}+\mathrm{G}_{\mathrm{k}}+\mathrm{E}_{\mathrm{ijk}} \quad \text { (Equation 1) }
$$

where, $Y_{i j k}$ is the observation for superovulation traits, $\mu$ is the overall population mean, $P_{i}$ is the fixed effect due to the i-th parity, $M_{j}$ is the fixed effect of $j^{\text {th }}$ months of age, $G_{k}$ is the fixed effect associated with $\mathrm{k}^{\text {th }}$ genotype ( $\mathrm{AA}, \mathrm{AB}$ and $\mathrm{BB}$ genotypes), and $E_{i j k}$ is random error. The significance of differences was tested using Duncan's multiple comparison. 


\section{RESULTS}

\section{Genotypes}

HIF-3a gene fragments were amplified from genomic DNA of all samples (Figure 1A). According to the three band patterns observed after the digestion reaction, the cattle were classified into three groups: $A A, A B$, and $B B$. The $C 278 G$ transition results in an amino acid change from proline to arginine, a polymorphism that destroys the restriction site recognized by the Alw44I endonuclease. As shown in Figure 1B, DNA restriction fragments at locus C278G were generated by the HIF-3a-Alw44I polymorphisms: 379 bp for the AA genotype (40 cattle), 101 and 278 bp for the BB genotype (68 cattle), and 101, 278, and 379 bp for the AB genotype (192 cattle). The sequencing results are shown in Figures $2 \mathrm{~A}$ and $\mathrm{B}-\mathrm{D}$.

A

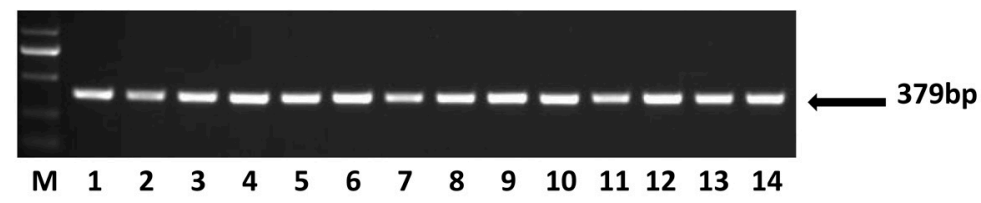

B

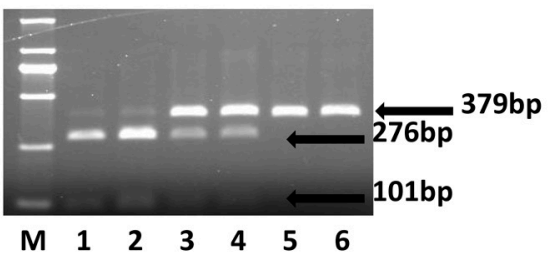

Figure 1. PCR-restriction fragment length polymorphism (RFLP) results for the HIF-3a gene in Changbaishan black cattle. A. PCR products of HIF-3a gene fragments analyzed using 1\% agarose gel electrophoresis. Lanes 1-14 refer to 14 PCR products selected from random samples. The arrow shows the expected 379-bp band of the HIF-3a gene fragments amplified from the genomic DNA of all samples. B. Representative RFLP genotypes of the HIF-3a gene fragment analysis using $2 \%$ agarose gel electrophoresis. Lanes 5 and 6 , with one band at $379 \mathrm{bp}$, refer to the AA genotype, lanes 1 and 2, with two bands at 101 and $278 \mathrm{bp}$, refer to the BB genotype, lanes 3 and 4, with three bands at 101,278 , and $379 \mathrm{bp}$, refer to the $\mathrm{AB}$ genotype, lane $M$ refers to the DL2000 marker.

\section{Associations of genotypes with superovulation traits}

Association analysis between HIF-3 $\alpha$ genotypes and superovulation traits are shown in Table 1. The three genotypes showed no significant difference in the number of available embryos (NAE), the number of M2 embryos, and the number of M1 embryos. The BB genotype had a greater number of unfertilized embryos than the AA genotype $(2.23 \pm 0.316$ versus 0.80 $\pm 0.197 ; \mathrm{P}<0.05)$. The BB genotype also had a greater number of degenerative embryos than the AA genotype $(3.97 \pm 0.491$ versus $2.03 \pm 0.461 ; P<0.01)$. The AB genotype did not differ significantly from the AA or BB genotype for either trait. Additionally, the BB genotype had a greater number of total embryos (NTE) than either the $A A$ or the $A B$ genotype $(P<0.01$ and $P<$ 0.01 , respectively). 


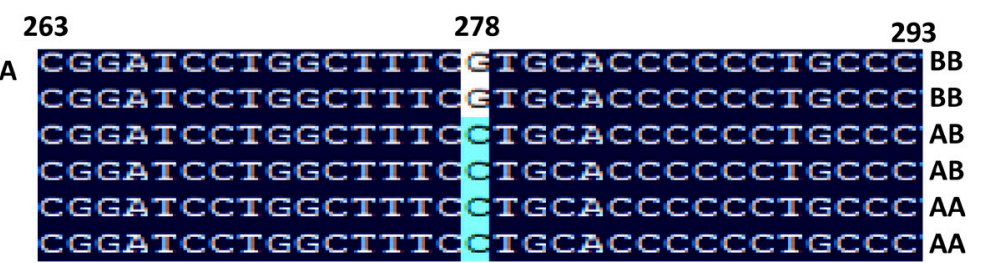

B

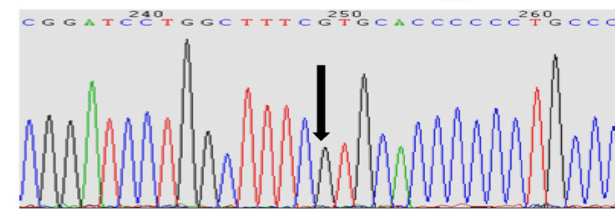

BB Genotype

C

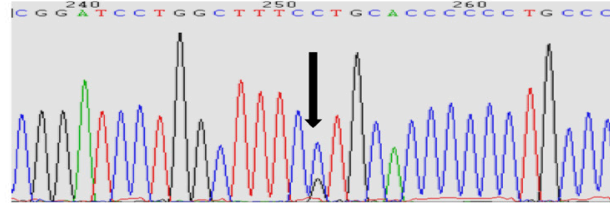

\section{AB Genotype}

D

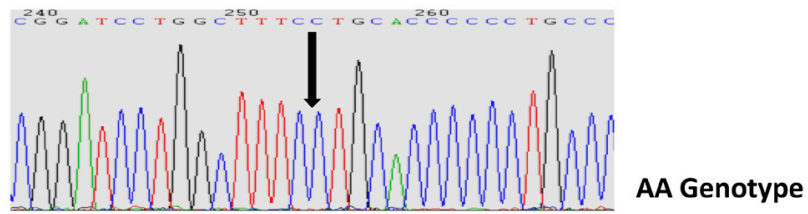

Figure 2. Sequencing results and sequence alignments of different genotypes in Changbaishan black cattle. A. Sequence alignment of the $A A, A B$, and BB genotypes. Sequence alignment shows a C278G transition in the HIF$3 \alpha$ gene fragments. B.-D. Sequencing of HIF-3a gene fragments. Representative sequencing results of the different genotypes: B. BB genotype, C. AB genotype, and D. AA genotype. The arrows indicate the mutation site and there are double peaks in the heterozygous $A B$ genotype.

Table 1. Association of genotypes for HIF-3a with superovulation traits in Changbaishan Black cattle.

\begin{tabular}{lccc}
\hline Superovulation traits & Genotype AA & Genotype AB & Genotype BB \\
\hline NUE & $0.80 \pm 0.197^{\mathrm{a}}$ & $1.70 \pm 0.198^{\mathrm{ab}}$ & $2.23 \pm 0.316^{\mathrm{b}}$ \\
NDE & $2.03 \pm 0.461^{\mathrm{A}}$ & $2.75 \pm 0.212^{\mathrm{AB}}$ & $3.97 \pm 0.491^{\mathrm{B}}$ \\
NAE & $7.95 \pm 0.728$ & $8.03 \pm 0.488$ & $10.12 \pm 1.025$ \\
NTE & $10.78 \pm 1.036^{\mathrm{A}}$ & $12.44 \pm 0.551^{\mathrm{A}}$ & $16.32 \pm 1.225^{\mathrm{B}}$ \\
NM2 & $1.10 \pm 0.286$ & $1.66 \pm 0.162$ & $1.79 \pm 0.230$ \\
NM1 & $5.90 \pm 0.572$ & $6.06 \pm 0.401$ & $7.88 \pm 0.895$ \\
NBE & $0.95 \pm 0.377^{\mathrm{a}}$ & $0.31 \pm 0.077^{\mathrm{b}}$ & $0.45 \pm 0.147^{\mathrm{a}}$ \\
PUE & $8.99 \% \pm 2.920 \%$ & $14.49 \% \pm 1.494 \%$ & $15.90 \% \pm 2.592 \%$ \\
PDE & $15.95 \% \pm 2.737 \%^{\mathrm{a}}$ & $23.10 \% \pm 1.542 \%$ & $24.65 \% \pm 2.722 \%$ \\
PAE & $75.06 \% \pm 4.187 \%^{\mathrm{a}}$ & $63.16 \% \pm 2.319 \%^{\mathrm{b}}$ & $59.57 \% \pm 3.489 \%^{\mathrm{b}}$ \\
PM1 & $67.36 \% \pm 4.466 \%^{\mathrm{a}}$ & $56.98 \% \pm 2.430 \%^{\mathrm{ab}}$ & $51.89 \% \pm 3.432 \%^{\mathrm{b}}$ \\
PBE & $6.55 \% \pm 2.394 \%^{\mathrm{A}}$ & $1.97 \% \pm 0.045 \%^{\mathrm{B}}$ & $3.50 \% \pm 1.161 \%^{\mathrm{AB}}$ \\
\hline
\end{tabular}

Superovulation traits correspond to the stereomicroscope observation. NUE = number of unfertilized embryos; NDE = number of degenerated embryos; NAE = number of available embryos; NTE = number of total embryos; NM2 = number of $\mathrm{M} 2$ embryos; NM1 = number of M1 embryos; NBE = number of blastulas; PUE = percentage of unfertilized embryos $=$ NUE $/$ NTE $\times 100 \% ;$ PDE $=$ percentage of degenerated embryos $=$ NDE $/$ NTE $\times 100 \% ; P A E=$ percentage of available embryos $=(\mathrm{NM} 1+\mathrm{NM} 2+\mathrm{NBE}) / \mathrm{NTE} \times 100 \% ; \mathrm{PM} 1=$ percentage of $\mathrm{M} 1 \mathrm{embryos}=(\mathrm{NM} 1+\mathrm{NBE}) / \mathrm{NTE} \times 100 \%$; $\mathrm{PBE}=$ percentage of blastulas $=$ NBE $/$ NTE $\times 100 \%$. Values with different lowercase letter superscripts in the same column differ significantly $(P<0.05)$. Values with different uppercase letter superscripts in the same column differ significantly $(P<0.01)$. 


\section{DISCUSSION}

Gene sequences and variations among them are the entry points for understanding gene expression and function (Liu et al., 2009). The function of transcriptional regulation may be changed by point mutations in the regulatory regions of genes that can alter configurations (Mayo et al., 2006). Using genetic screening, mutations involving defects in transcriptional regulation have been found for developmentally important genes (Gibson and Honeycutt, 2002). Mutations can be a useful tool for animal breeding and production due to such alternations in transcriptional regulation. However, few mutations have been discovered compared to the number of genes.

Maintaining oxygen homeostasis is essential to all higher organisms for proper development, growth, and maintenance of tissue structural integrity. In general, HIFs are vital to proper development and deletion of the HIF-1 $\alpha$ gene results in prenatal death. HIFs are crucial for oxygen homeostasis during both embryonic development and postnatal life (Yamashita et al., 2008).

The third $\alpha$-class of HIF subunits was first isolated in the mouse (mHIF-3 $\alpha$ ) in 1998 (Gu et al., 1998). The human homologue of the $m H I F-3 \alpha$ (hHIF-3 $\alpha$ ) was later isolated and shown to have high homology to $h H I F-1 \alpha$ and $-2 \alpha$ (Hara et al., 2001), raising the possibility that it may also be involved in adaptive responses to changes in oxygen tension. The protein encoded by this gene is the alpha-3 subunit of one of several alpha/beta-subunit heterodimeric transcription factors that regulate many adaptive responses to low oxygen tension. The alpha-3 subunit lacks the transactivation domain found in factors containing either the alpha-1 or alpha-2 subunits. It is thought that factors containing the alpha- 3 subunit are negative regulators of hypoxia-inducible gene

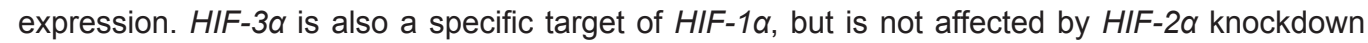
(Hara et al., 2001). Our experiments were designed to locate and identify SNPs in HIF-1 $\alpha$ exons, but we found no SNP sites in our cattle herds. We hypothesize that the SNP may have an effect

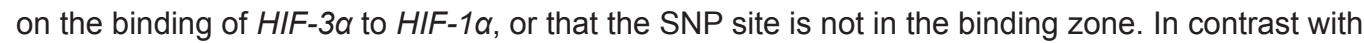
$H I F-1 \alpha$ and HIF-2 $\alpha, H I F-3 \alpha$ is not regulated at the protein level. The HIF-3a protein can be detected under normoxic conditions in the cytoplasm and nuclei, but increases under hypoxic conditions (Tanaka et al., 2009). At least six different splice variants, hHIF-3 $\alpha$ 1-6 (Maynard et al., 2003) may be expressed from the human HIF-3 $\alpha$ locus, suggesting it may exert a primarily negative regulatory effect on hypoxic gene induction (Tanaka et al., 2009).

The functional properties of HIF-3 $\alpha$ are still unknown. A study by Heidbreder et al. (2003)

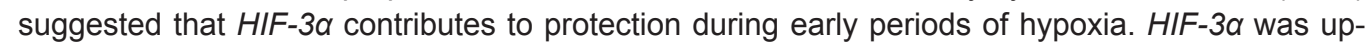
regulated by severe and/or sustained hypoxia and was strongly induced by hypoxia $\left(1 \% \mathrm{O}_{2}\right)$ both at the protein and mRNA level due to an increase in protein stability and transcriptional activation (Heidbreder et al., 2003). The hypoxic induction of HIF-3 $\alpha$ protein is also dependent on the duration of the hypoxic conditions. HIF-3 $\alpha$ protein increased rapidly within $30 \mathrm{~min}$ of exposure to $1 \% \mathrm{O}_{2}$ and increased further with a longer exposure to hypoxia, indicating that hypoxia stabilized this protein ( $\mathrm{Li}$ et al., 2006). Low oxygen tension leads to the stabilization of the $\alpha$-subunit, nuclear translocation, and recruitment of transcriptional co-activators (Kallio et al., 1998). In a further investigation, we attempted to locate the regulator of HIF-3a mRNA expression. As it is shown in Figure S1, we failed to detect expression of HIF-3 $\alpha$ in the germinal vesicle oocyte or 16-cell embryo, and the 4-cell embryo had the highest expression, approximately 5.6-fold more than the metaphase II (MII) oocyte $(P<0.01)$. Among the five developmental stages, morulae had the lowest expression levels of HIF-3a, approximately 0.08 -fold compared to MII oocyte levels ( $\mathrm{P}<0.05$ ). MII oocytes, 2 -cell, and 8-cell embryos had similar expression levels, indicating that there was little or no HIF-3a mRNA expression during these developmental stages. During folliculogenesis, artificial insemination 
and early embryonic development, the oocyte/zygote is under normal oxygen tension. However, absence of HIF-3 $\alpha$ mRNA expression during the 16-cell stage needs to be investigated further. During the 16-cell stage, the embryo crosses the 8 to 16 cell bovine embryonic blockade and is then able to transport oxygen to the inner blastomeres for normal metabolism; therefore, $H I F-3 \alpha$ mRNA is down-regulated. The specific mechanism behind this process needs further investigation.

The 4-cell embryo had the highest expression of HIF-3 $\alpha$ mRNA and the other three types of embryo had almost the same expression levels as each other. This is the first time that $H I F-3 \alpha$ mRNA expression patterns in bovine embryos/oocytes have been reported. The low expression of HIF-3a mRNA in the morulae stage corresponds to its inferred function to prevent cells from differentiating. When the embryo reaches the blastocyst stage, it starts to differentiate into several mesoderms. However, when the embryo starts to differentiate, HIF-3 $\alpha$ mRNA is down-regulated by regulatory mechanisms.

We conclude that oxygen tension was lowest during the 4-cell stage and highest during the 16-cell stage of development. The low oxygen tension during the 4-cell stage may be due to the long culture time. Lower expression of HIF-3 $\alpha$ mRNA in the 8-cell stage compared to the 4-cell stage may be due to developmental heterogeneity because some of the embryos had passed, or were in the process of passing the blockade. Genetic and environmental factors may have also been involved. For hypoxic stabilization, the activity of $H I F-1 \alpha$ is modulated by phosphorylation via the mitogen-activated protein kinases or the phosphatidylinositol 3-kinase pathway (Richard et al., 1999; Zhong et al., 2000).

In this study, we compared the association of a polymorphism with superovulation and found that cattle with genotypes AA and BB differ significantly in their superovulation traits. This is the first report to detect the association of HIF-3 $\alpha$ mRNA expression with superovulation traits. The polymorphism of the HIF-3a gene has a significant effect on a number of superovulation traits. The numbers of cattle with $A A, A B$, and BB genotypes were 40,192 , and 68 , respectively. It appears that the heterozygous genotype is more abundant and accounts for approximately two-thirds of all cattle in our herds. The genotype frequency of $A A: A B: B B$ was approximately $1: 4.8: 1.7$, and the allele gene frequency of $A: B$ was approximately $1: 1.2$, indicating that $A B$ is the dominant genotype and the $B$ allele is the dominant allele. As shown in Table 1, all of the superovulation traits showed that the BB genotype cattle were the most abundant and AA genotypes were the least abundant. Based on NAE and NTE, the BB genotype may be better suited for daily production requirements.

We conclude that the HIF-3 $\alpha$ gene may be involved in the whole process of superovulation treatment, especially during early embryonic development. HIF-3 $\alpha$ influences the number of embryos as well as the corresponding percentage. HIF-3 $\alpha$ may serve as a molecular marker in donor selection for superovulation treatment.

\section{Conflicts of interest}

The authors declare no conflict of interest.

\section{ACKNOWLEDGMENTS}

Research supported by the earmarked fund for Modern Agro-industry Technology Research System (\#CARS-38), the Key Program for Science and Technology Development of Jilin Province (\#20140204077NY), the program of IRT1248, and the Cooperative Extension Specialist, Jilin Province Beef Cattle Industrial Technology System. The authors thank the staff for their technical assistance during the superovulation treatments at the Beijing Anbo Embryo Technology Co., Ltd. and cattle breeding farm. 


\section{Supplementary material}

\section{REFERENCES}

Fauser BC, Diedrich K and Devroey P (2008). Predictors of ovarian response: progress towards individualized treatment in ovulation induction and ovarian stimulation. Hum. Reprod. Update 14: 1-14.

Genbacev O, Krtolica A, Kaelin W and Fisher SJ (2001). Human cytotrophoblast expression of the von Hippel-Lindau protein is downregulated during uterine invasion in situ and upregulated by hypoxia in vitro. Dev. Biol 233: 526-536.

Gibson $G$ and Honeycutt E (2002). The evolution of developmental regulatory pathways. Curr. Opin. Genet. Dev. 12: 695-700.

Gu YZ, Moran SM, Hogenesch JB, Wartman L, at al. (1998). Molecular characterization and chromosomal localization of a third alpha-class hypoxia inducible factor subunit, HIF3alpha. Gene Expr. 7: 205-213.

Hara S, Hamada J, Kobayashi C, Kondo Y, et al. (2001). Expression and characterization of hypoxia-inducible factor (HIF)3alpha in human kidney: suppression of HIF-mediated gene expression by HIF-3alpha. Biochem. Biophys. Res. Commun. 287: 808-813.

Hasler JF (2003). The current status and future of commercial embryo transfer in cattle. Anim. Reprod. Sci. 79: 245-264.

Heidbreder M, Frohlich F, Johren O, Dendorfer A, et al. (2003). Hypoxia rapidly activates HIF-3alpha mRNA expression. FASEB J 17: 1541-1543.

lyer NV, Kotch LE, Agani F, Leung SW, et al. (1998). Cellular and developmental control of $\mathrm{O}_{2}$ homeostasis by hypoxiainducible factor 1 alpha. Genes Dev. 12: 149-162.

Kallio PJ, Okamoto K, O'Brien S, Carrero P, et al. (1998). Signal transduction in hypoxic cells: inducible nuclear translocation and recruitment of the CBP/p300 coactivator by the hypoxia-inducible factor-1alpha. EMBO J 17: 6573-6586.

Lee YM, Jeong CH, Koo SY, Son MJ, et al. (2001). Determination of hypoxic region by hypoxia marker in developing mouse embryos in vivo: a possible signal for vessel development. Dev. Dyn. 220: 175-186.

Li QF, Wang XR, Yang YW and Lin H (2006). Hypoxia upregulates hypoxia inducible factor (HIF)-3alpha expression in lung epithelial cells: characterization and comparison with HIF-1alpha. Cell Res. 16: 548-558.

Lindner GM and Wright RW Jr (1983). Bovine embryo morphology and evaluation. Theriogenology 20: 407-416.

Liu JJ, Ran XQ, Li S, Feng Y, et al. (2009). Polymorphism in the first intron of follicle stimulating hormone beta gene in three Chinese pig breeds and two European pig breeds. Anim. Reprod. Sci. 111: 369-375.

Mapletoft RJ and Hasler JF (2005). Assisted reproductive technologies in cattle: a review. Rev. Sci. Tech. 24: 393-403.

Maynard MA and Ohh M (2004). Von Hippel-Lindau tumor suppressor protein and hypoxia-inducible factor in kidney cancer. Am. J. Nephrol. 24: 1-13.

Maynard MA and Ohh M (2007). The role of hypoxia-inducible factors in cancer. Cell. Mol. Life. Sci. 64: 2170-2180.

Maynard MA, Qi H, Chung J, Lee EH, et al. (2003). Multiple splice variants of the human HIF-3 alpha locus are targets of the von Hippel-Lindau E3 ubiquitin ligase complex. J. Biol. Chem. 278: 11032-11040.

Mayo AE, Setty Y, Shavit S, Zaslaver A, et al. (2006). Plasticity of the cis-regulatory input function of a gene. PLoS Biol. 4: e45.

Peng J, Zhang L, Drysdale L and Fong GH (2000). The transcription factor EPAS-1/hypoxia-inducible factor 2alpha plays an important role in vascular remodeling. Proc. Natl. Acad. Sci. U.S.A. 97: 8386-8391.

Richard DE, Berra E, Gothie E, Roux D, et al. (1999). p42/p44 mitogen-activated protein kinases phosphorylate hypoxiainducible factor 1alpha (HIF-1alpha) and enhance the transcriptional activity of HIF-1. J. Biol. Chem. 274: 32631-32637.

Tanaka T, Wiesener M, Bernhardt W, Eckardt KU, et al. (2009). The human HIF (hypoxia-inducible factor)-3alpha gene is a HIF-1 target gene and may modulate hypoxic gene induction. Biochem. J. 424: 143-151.

Tian H, Hammer RE, Matsumoto AM, Russell DW, et al. (1998). The hypoxia-responsive transcription factor EPAS1 is essential for catecholamine homeostasis and protection against heart failure during embryonic development. Genes Dev. 12: 3320-3324.

Wang GL, Jiang BH, Rue EA and Semenza GL (1995). Hypoxia-inducible factor 1 is a basic-helix-loop-helix-PAS heterodimer regulated by cellular $\mathrm{O}_{2}$ tension. Proc. Natl. Acad. Sci. U.S.A. 92: 5510-5514.

Wenger RH and Gassmann M (1997). Oxygen(es) and the hypoxia-inducible factor-1. Biol. Chem. 378: 609-616.

Yamashita T, Ohneda O, Nagano M, Lemitsu M, et al. (2008). Abnormal heart development and lung remodeling in mice lacking the hypoxia-inducible factor-related basic helix-loop-helix PAS protein NEPAS. Mol. Cell. Biol. 28: 1285-1297.

Zhong H, Chiles K, Feldser D, Laughner E, et al. (2000). Modulation of hypoxia-inducible factor 1alpha expression by the epidermal growth factor/phosphatidylinositol 3-kinase/PTEN/AKT/FRAP pathway in human prostate cancer cells: implications for tumor angiogenesis and therapeutics. Cancer Res. 60: 1541-1545. 